Fecha de recepción: febrero 2019

Fecha de aceptación: marzo 2019

Versión final: mayo 2019

\section{Una mirada al cartel}

Diego Bermúdez Aguirre*

Resumen: El presente texto forma parte del proyecto de investigación doctoral El cartel publicitario colombiano: la modernización de Cali a través de la estampa (1910-1944), que el autor está adelantando en la actualidad en el Doctorado de Historia y Artes de la Universidad de Granada (España). Este texto tiene como temática principal la Historia del Diseño Gráfico, y su contenido se ocupa del cartel como objeto cultural y sus características principales. El cartel publicitario es una ventana y un espejo en el cual se puede comprender a una sociedad en un periodo de tiempo específico, razón por la cual, los carteles se han constituido en referencia del mundo moderno.

Palabras clave: Historia del Diseño - diseño - Diseño Gráfico - Diseño Publicitario - cartelería.

[Resúmenes en inglés y portugués en las páginas 43-44]

(*) Estudiante del Doctorado en Historia y Artes de la Universidad de Granada (España) Profesor Asociado de la Pontificia Universidad Javeriana Cali (Colombia). Integrante de la Design History Society (UK), Design Resarch Society (UK) y Fundació Història del Disseny (ES).

La industrialización y el desarrollo de mercados de bienes de consumo, llevaron al cartel a convertirse en un medio de comunicación de masas a partir de 1870, lo que significó que aumentaran de manera drástica los tirajes y tamaños manejados por los carteles hasta ese entonces. La aparición de la imprenta en el siglo XV, no fue suficiente para la masificación del cartel, ya que ésto solo se logró hacia mediados del siglo XIX con el desarrollo de la litografía y posteriormente la cromolitografía, la cual se define como un proceso de impresión serializado a color de alta velocidad. Así, las paredes de las ciudades modernas (París, Londres, Berlín, New York, Roma, Madrid, etc.) se fueron convirtiendo en un escaparate de anuncios, manifestándose como el terreno de batalla donde la emergente burguesía buscaba consolidar su proyecto industrializador y lograr un ascenso económico respaldado por la gráfica publicitaria encarnada en la cartelería. De esta manera, no solo encontró allí un medio eficaz para dar a conocer sus servicios o bienes, sino construyó un sistema capaz de garantizar ganancias constantes a medida que desempeñaba su producción comercial (Coronado, 2002, p. 52). 
Así, la aparición del cartel moderno en la segunda mitad del siglo XIX, como hijo ilustrado de la revolución industrial, estuvo ligado al surgimiento de una nueva clase y a un nuevo poder representado en la burguesía y su nueva forma de producción (la industria), las cuales buscaban identificarse con una nueva imagen y una innovadora estética que se encarna en la gráfica publicitaria. Por ello, el cartel publicitario logró materializarse como la imagen más representativa de ese nuevo orden social y político instituido por el poder económico, poniendo de manifiesto intereses y posturas diferentes a las existentes hasta ese momento (Hutchinson, 1968, p. 19).

\section{Características fundamentales del cartel}

El cartel, esa máquina para anunciar como lo definiera el grafista franco-ucraniano A. M. Cassandre, es el medio de representación que encarna muchos de los aspectos esenciales para hacer pública una idea de manera eficiente (Spiess, 1987, p. 33). Josef Müller-Brockmann en su libro History of the Poster, plantea una serie de requerimientos que el cartel debe cumplir. Se exige que su imagen sea legible para que su mensaje sea comprensible por el público que lo observa. Así, puede despertar el interés del observador con un manejo innovador de la imagen y el texto en un formato generoso que corresponda con eficiencia al tipo de información que transporta. El cartel debe definirse en términos que sea efectiva su lectura a distancia, por ende, la tipografía debe ser clara y a un tamaño adecuado. De la misma manera, su lenguaje gráfico debe ser apropiado de acuerdo al contenido y al contexto en el cual se realiza el cartel. El ordenamiento de la información gráfica-textual debe permitir su lectura rápida y eficaz, así es posible crear un vínculo nmotécnico en el observador. Así mismo, el color debe ser un complemento visual que ayude a clarificar la lectura, gracias a sus valores simbólicos que pueden enfatizar el aspecto económico, social, político o cultural del mensaje. Por último, el ángulo visual y el encuadre del cartel deben emplearse como un refuerzo de la imagen, tanto a nivel visual, como a nivel semántico (Müller-Brockmann, 1971, p. 21).

Para dar cumplimiento a los postulados anteriores, el cartel, desde el punto de vista de su concepción, se debe caracterizar por ser un producto que sea simple en su configuración (forma, color, trazo, tono, textura, tipografía) y de contenido (mensaje). Teniendo en cuenta su realización, el cartel debe ser sencillo en la elaboración de su gráfica, así como en la composición de sus textos, los cuales se recomiendan que no sean muy extensos para que sean leídos de manera rápida. En cuanto la planificación de medios, el cartel debe ser de fácil lectura y de inmediata comprensión por parte del público. Así, debe estar a la altura adecuada y tener el formato que facilite el proceso de transmisión del mensaje, logrando que la idea expresada en el cartel sea recordada por el observador, generando una reacción posterior de acuerdo a un objetivo de comunicación y marketing. En esa misma dirección, y teniendo en cuenta su consumo, el cartel se caracteriza por primar la obra múltiple sobre el original, acabando con el aura de imagen única que termina siendo reproducida de manera serial con el objetivo de cautivar la atenta mirada de los transeúntes (Coronado, 2002, p. 63). 


\section{Funciones y competencias del cartel}

Un cartel debe atraer la atención del observador, debe informarle y generarle curiosidad para que realice una acción, por lo cual, es necesario que utilice un lenguaje propio de una audiencia específica (Glaser, 1981, p. 9). Siguiendo ese orden de ideas, se puede vislumbrar algunas de las finalidades propias del cartel que ya se han manifestado en este texto, entre las cuales están su función informativa, de convicción, económica, estética, creadora y ambiental (Müller-Brockmann, 1971, p. 78). A las anteriores, François Enel le agregaría la función aseguradora, por la cual el cartel cumple una tarea emancipadora esencial, ofreciendo a través del producto que ofrece un escenario verosímil, seguro y creíble que liberan al consumidor de todos los problemas contemporáneos que lo acechan (Enel, 1974, p. 107).

El propósito primordial de un cartel es representar fielmente las propiedades fundamentales de un producto o una idea, con el objetivo de alcanzar los máximos beneficios entre la sociedad. Lo anterior se logra materializar a partir de la eficiencia de la imagen, respetando las características del entorno en el cual el cartel se desenvuelve. Por ello, el cartel publicitario debe dar cumplimiento a su responsabilidad de llevar consigo un mensaje comercial de manera oportuna, precisa y clara, para su posterior aceptación por parte del público. Todo lo anterior, ha ido de la mano con los movimientos artísticos y corrientes estéticas de cada época, lo que ha contribuido a la evolución formal y comunicativa del cartel (Checa, 2015, p. 84).

Por todo ello, se puede hablar de cinco exigencias (competencias) básicas propias del cartel. La primera de ellas, la COMPETENCIA INFORMATIVA, se refiere a la naturaleza del cartel como un medio destinado en dar a conocer un producto y/o un mensaje específico. Posteriormente, la COMPETENCIA PERSUASIVA busca que el público se motive movilizar su conducta a partir de la información que se presenta en el cartel. Para lograr lo anterior, a partir de la COMPETENCIA ESTÉTICA, es necesario que el discurso manifiesto en el cartel se exprese de una manera atractiva y original. Así, el observador se relaciona con lo que observa en el cartel y los significados que allí se exponen, de acuerdo a un interés comunicativo del emisor del mensaje. La COMPETENCIA EDUCADORA se refiere a la tarea que tiene encargada el cartel de entrar a modificar hábitos, cómportamientos e ideas para el mejoramiento de la calidad de vida, así como de ofrecer diferentes aspectos de conocimiento e información, hasta ese entonces desconocida por parte del público. Por último, la COMPETENCIA URBANÍSTICA Y AMBIENTAL, se refiere a la búsqueda de adaptabilidad y respeto a las normas básicas del entorno urbano al momento de insertar los carteles en las paredes y muros de las ciudades (Coronado, 2002, p. 51).

\section{La retórica del cartel: la relación palabra-imagen}

El cartel en un principio, tuvo sus orígenes en la necesidad social de construir un artefacto que sirviera para anunciar públicamente una idea o producto en las paredes de las calles, para que su mensaje fuera recibido por cualquier persona sin distingo de ninguna clase. En 
él, se hace evidente la noción moderna de lo público, según la cual, los integrantes de una sociedad se determinan como espectadores y consumidores. Lo anterior se desprende del concepto moderno de espacio público, entendido como teatro de persuasión, en donde el terreno se colmaba de signos, presentes en fachadas y paredes, con el fin de buscar reacciones entre los ciudadanos. De esta manera, los carteles más allá de informar, buscaban seducir, convencer, convocar y atraer a través de la elocuencia de la gráfica, la cual, debía imponerse sobre el resto de carteles con los cuales compartía las paredes citadinas (Sontag, 1999, p. 3). La relación entre lo textual y lo icónico, uno de los aspectos más representativos del lenguaje de la cartelería, es solo una expresión de la propia tradición cultural occidental, en la cual, la palabra y la imagen se han constituido en sistemas modelizadores de la cultura en la transmisión de los mensajes. Es por ello que toda imagen puede ser asumida como un texto, de la misma manera que todo texto trae una imagen a la cual remite, tarea que los carteles ponen en evidencia al configurar un mensaje de manera total, sin importar que éste sea de carácter textual o icónico. (Alcacer, 1991, p. 108). A partir de los carteles de Jules Chéret en la segunda mitad del siglo XIX, la tipografía, representación formal de la palabra, comenzó a hacer las veces de imagen y signo visual en función de la claridad del mensaje, integrándose al lenguaje de las ilustraciones al ser dibujados los textos, conforme a una lógica más cercana a la imagen. Estos trabajos de Chéret, considerado el padre del cartel moderno, fueron los primeros ejemplos donde el texto se convirtió en imagen, pero no de una realidad referenciada sino de sí mismo como imagen diferenciada desde el punto de vista formal y de contenido, con la intención de ser reconocida, asociada y recordada por el observador en el tiempo (Barnicoat, 2002, p. 37).

A partir del carácter dual de los carteles (icónico y textual), representado en lo gráfico y lo lingüístico, se sustituyó la oposición imagen/texto por la intencionalidad de hacer visible y legible el mensaje allí presente. Así, se hizo necesario una decodificación que permitiera la comprensión y entendimiento del mensaje, de la mano con las condiciones naturales de la mirada sin entrar a distinguir entre lo icónico y lo textual. Ante la presencia de un cartel, lo que se antepone es la relación establecida entre el observador y el producto anunciado a través de la capacidad imaginaria que inaugura la mirada (Coronado, 2002, p. 92).

El cartel, como medio impreso en el cual el protagonismo de la imagen se fundamenta en la complementariedad y cohabitación con el texto escrito, hizo posible que la información que necesitaba ser anunciada públicamente dejara de ser vociferada en las calles por pregoneros propios de la Edad Media, al transformarse esos gritos en frases impresas e ilustradas en un papel para ser pegadas en las paredes de las calles citadinas. A partir del origen oral del mensaje publicitario, los carteles se convirtieron en un medio de comunicación de naturaleza eminentemente visual, en un entorno donde la cultura era de tradición escrita. Lo anterior, se convertiría en uno de los principales cambios que el cartel vino a propiciar en el desarrollo de la era moderna, la cual, se inauguró, entre otras cosas, con el surgimiento y perfeccionamiento de la imprenta, además del establecimiento de un nuevo sistema económico fundamentado en el libre intercambio y consumo de productos y servicios, actividades en las cuales el cartel tendría muchas cosas que decir.

El lenguaje del cartel se fundamentó en la necesidad de transmitir un mensaje por la sola presencia pública de la imagen en espacios comunitarios. Allí, la seducción propia de la 
imagen, iba de la mano con la búsqueda de eficacia comunicativa para que el mensaje fuera asimilado con rapidez y claridad (Gubern, 1987, p. 8). Así, lo elementos icónicos del cartel, no se fundamentan como mímesis de representación, sino en el reconocimiento analógico del mundo, ya que sus componentes deben ser decodificados con rapidez y facilidad. Sin embargo, en la imagen del cartel prevalecerá el valor simbólico más allá de sus aspectos de carácter referencial, dado que predominan los aportes imaginarios de la imagen sobre lo informativo de su contenido. Texto e imagen, establecen una relación de intercambio que varía desde la predominancia de lo icónico que reduce lo textual a simple inscripción, hasta el protagonismo del texto que minimiza la presencia de la imagen al funcionar por sí mismo como tal. El contenido del cartel es percibido y decodificado como un todo continuo que posibilita pasar de un registro (texto) a otro (imagen) en un mismo nivel de reconocimiento como elementos significantes de un mismo enunciado (Coronado, 2002, p. 116).

La integración en un mismo nivel de lectura del texto y la imagen en un cartel, permite adentrarse en el nivel del relato. En este punto, la retórica se establece como uno de los recursos más importantes al momento de analizar la eficacia comunicativa que persiguen los mensajes presentes en los carteles, haciendo uso de algunos procedimientos retóricos para alcanzar sus objetivos. En ese sentido, la cartelería se alimenta de estos recursos como la elipsis (supresión de parte o de la totalidad de los elementos de una imagen), el sinécdoque (supresión parcial de un elemento utilizando esa parte para designar la totalidad), la metonimia (supresión parcial de un elemento que se sustituye por otro), la metáfora (uso de un elemento en sustitución de otro de cualidades análogas), la alegoría (uso de un contexto en sustitución de otro de cualidades análogas), el quiasmo (reiteración de un contexto pero intercambiando el orden de sus elementos), la antítesis (contraposición de sentido entre dos elementos), la hipérbole (alteración desproporcionada de una parte o cualidad de un elemento), aliteración (repetición de elementos semejantes), la ironía (presentación satírica y burlesca de elementos) o la paradoja (presentación de aspectos incompatibles). Pero la retórica del cartel no se reduce únicamente al uso de figuras de dicción y tropos visuales o icónico-textuales. Es común escuchar expresiones la parte por el todo, el todo por la parte, el género por la especie, el singular por el plural, un término por otro, una cosa por otra, la alteración exagerada e intencional de la realidad, la identificación de un término o cosa real con algo imaginario. Es así como el cartel se expone, se pone fuera y adopta la misma condición de un cuadro en su exposición inaugural. Un cartel es una cosa, una pieza, un elemento nuevo en la calle, es otro modo de decir algo. Color, imagen, tipografía e ideas hacen de esta obra un producto de diseño y pieza de comunicación, un foco de atención, una llamada que se ofrece al observador. Serlo es, en cierto modo, uno de sus propósitos y, de hecho, en serlo radica su éxito (Morelos, 2016, p. 61).

\section{La estética del cartel}

A partir de la manifestación de la utopía cultural que se representa en el marco del diseño gráfico, se materializa en la búsqueda de la satisfacción de necesidades sociales, de comu- 
nicación, seducción, convocatoria y persuación, como es en el caso específico de la cartelería. En ese escenario es donde el cartel vino a aportar en gran medida en el rompimiento del mito de la hegemonía estética del arte, ya que lo diseñado se desarrolla en el propio seno de la producción económica industrial.

De esta manera, la realización de un cartel está asociada a la producción planificada, bajo requisitos de carácter técnico, simbólico, estéticos y utilitarios, los cuales, se diferencian de manera importante de la manera de producción simbólica del arte, surgiendo el cartelista como un agente de cambio que da respuestas funcionales y prácticas a requerimientos sociales específicos y concretos nacidos de la cotidianidad de la sociedad contemporánea (Bermúdez, 2015, p. 672).

Según Norberto Chaves, la cartelería centra sus intereses estéticos en la capacidad para generar mensajes que permitan la constitución de hechos visuales abstractos, con valores eminentemente formales, los cuales, son susceptibles de seducir y persuadir de manera consciente o inconsciente a los observadores, y con ello, favorecer así su aceptación como hecho estético válido (Chaves, 1989, p. 6). Por esta razón, el acento existente en la satisfacción de este interés estético, es lo que posibilita que algunos carteles se ubiquen posteriormente en las paredes de los cuartos, tal cual como si fueran cuadros y que además, lleguen a reimprimirse únicamente para este fin.

Esta dimensión estética, suele manifestarse por vía de la gratificación, como un medio de potenciación de la función persuasiva y, por vía de la seducción, como un medio en potenciación de la búsqueda del interés comunicativo y de contacto. Ejemplo claro de ello es el olor que expelen algunos animales cuando están en celo o el color de las flores cuando están a punto para la polinización. Allí la naturaleza expone una idea muy clara y precisa de los servicios comunicacionales de la estética, asunto que los carteles han intentado seguir al pie de la letra.

Tal como lo expresa el cartelista e investigador mexicano José Manuel Morelos, el cartel como objeto artístico, producto de diseño y pieza de comunicación, recoge en su discurso ideas de función y multiplicación, pues este satisface necesidades específicas y cumple con cierto tipo de requerimientos que van más allá de los espirituales o emocionales. La cartelería se produce por encargo y se fundamenta en la multiplicación y producción serial, oponiéndose al tan preciado valor de la unicidad de la obra artística. Pero ello no significa que una gran cantidad de obras artísticas dejen de serlo porque han servido a diversos propósitos desde la antigüedad hasta nuestros días. Tal es el caso del barroco, que desempeñó una importante función en torno a los conflictos religiosos que siguieron a la Reforma de Lutero. Frente a los protestantes, que proponían edificios sobrios, austeros, sin decoración para el culto, la iglesia católica respondió con la grandiosidad y la complejidad barrocas. Así, el barroco se convirtió en la expresión estética de la contrarreforma. Además, en América durante la colonia, se le empleó como medio para catequizar a los indígenas. Ejemplo de ello es el uso de diversas maneras del lenguaje barroco para contar historias bíblicas, así como la vida de santos, lo que contribuyó a imponer la nueva religión cristiana a los nativos latinoamericanos. Esta es una muestra de cómo la arquitectura, la pintura, la música, la escultura, el teatro y el cine, se han utilizado para inducir, contagiar, homogenizar, inhibir, promover ideas y conductas a lo largo de la historia (Morelos, 2016, p. 64). 


\section{Géneros y estilos del cartel}

Distintos autores ponen a consideración diferentes tipologías respecto a los carteles, a partir de criterios significativos, entre ellos de carácter tecnológico, estéticos, por las características del emisor, y por el tipo de contenido del cartel. La tecnología de impresión de la cartelería ha condicionado no solo su producción, sido también su forma, su lenguaje y sus posibilidades estéticas. De esta manera, procedimientos de impresión como la xilografía, la tipografía, la litografía, la serigrafía, el offset, la fotomecánica y desde finales del siglo XX la impresión digital, han sido los procedimientos más determinantes en la historia del cartel. El criterio estético se centra en los carteles configurados a partir de un interés artístico más allá de lo divulgativo, siendo el cartel de autor su principal representante. El tipo de emisor de los carteles se divide entre emisores privados, públicos y mixtos, cada uno con diferentes intereses de divulgación de sus productos, ideas, servicios e informaciones. Las características del contenido presente en un cartel se definen entre publicitarios y propagandísticos, a partir de temáticas comerciales, culturales y políticas (Eguizábal, 2014, p. 18).

Müller-Brockmann presenta una clasificación de la cartelería a partir de múltiples características, tanto temáticas como intencionalidades, definiéndolos entre carteles ilustrados, carteles objetivo-informativos, carteles constructivistas y carteles experimentales (MüllerBrockmann, 1971, p. 28). Esta división ha sido atacada ya que según algunos estudiosos en el tema del cartel, no se evidencia un criterio concreto que fundamente esta clasificación, considerándola excluyente, tanto así, que algunos carteles pertenecientes a una categoría, podrían perfectamente formar parte de otra.

Antonio Checa por su parte, afirma que los carteles, más allá de sus características formales, establecen una tipología que permiten clasificarlos de acuerdo al contenido y los mensajes que emiten. De esta manera, la cartelería se puede organizar en géneros a partir de los objetivos comunicativos que persiguen, de allí surgen los carteles publicitarios, políticos e institucionales (Checa, 2017, p. 39).

Los carteles publicitarios, nacieron de la mano de la burguesía en su búsqueda de beneficios económicos, ya que al ser productora de bienes de consumo, necesitaban un medio que publicitara (hiciera público) los productos y servicios que ofrecían al mercado. Detrás de este objetivo de carácter eminentemente comercial, se escondía la intención del emisor en generar un comportamiento concreto como adquirir y consumir determinado producto y/o servicio, convocar a un espectáculo, dirigirse a algún lugar en particular, entre otros. De esta manera, se estaban generando nuevas necesidades, disfrazadas en la provocación por adquirir algo que no se tenía, buscando incidir sobre la manera de actuar de los ciudadanos, los cuales, comenzaron a ser vistos como consumidores en potencia. Es en ese escenario, a finales del siglo XIX donde la figura de la mujer comenzó a ser explotada desde sus posibilidades de seducción como objeto de deseo. La presencia de Loïe Fuller en los carteles de Jules Chéret, Jane Avril en los de Henri de Toulouse-Lautrec y Sarah Bernart en los Alphonse Mucha son ejemplo claro de ello (Bierut, 1999, p. 218). 
El cartel político tiene como principal finalidad la difusión de una ideología incidiendo en la manera de pensar, todo encaminado en la promoción de diferentes ideas políticas representadas en los partidos políticos y sus candidatos, los cuales eran exaltados como representantes ideales de valores sociales. Así, la cartelería se estableció en un vehículo para alcanzar el poder, para la socialización de una ideología o para la exaltación de aquello que persigue transformaciones políticas, y ello lo lograría difundiendo ideas para defender o atacar, de acuerdo a la postura que se tuviera. Las reivindicaciones obreras del siglo XIX usaron de manera protagónica el cartel como apoyo a sus peticiones, por lo que diferentes movimientos sociales siguieron ese ejemplo. Las luchas en pro de los derechos de la mujer y de las minorías étnicas, movilizaciones estudiantiles, procesos revolucionarios y nacionalistas, entre muchos otros lo hicieron. De igual manera, gobiernos establecieron comités de propaganda para controlar o persuadir a sus ciudadanos apelando al uso de mensajes con un lenguaje basado en diferentes aspectos de la imaginería popular.

Por último, el cartel institucional tiene entre sus características la introducción de mensajes emitidos por organismos estatales, ONGs e instituciones de carácter social, que se relacionan con temáticas como buenas prácticas y valores gubernamentales y empresariales, así mismo, destacar esfuerzos en contra de enfermedades y asperezas propias de la vida real (Coronado, 2002, p. 161).

Por todo ello, el cartel se ha establecido como unidad antropológica que pone en evidencia una cultura de época, presentando creencias, imágenes y argumentos, a través de su carácter de síntesis cultural, lo que le ha permitido convertirse en uno de los elementos esenciales del análisis urbano contemporáneo. Así, su aparición en las paredes de las ciudades es muy significativa ya que hace evidente la transformación de la ciudad, configura un paisaje urbano de imágenes insistentes, evocadoras, sugerentes y persuasivas que en algunas oportunidades ofrece paternales consejos. La cartelería, en su diversidad, se estructura como unidad de deseo en un escenario urbano cambiante, sirviendo de elemento aglutinador de la comunicación social y determinador de una filosofía común que se presume extraída -análisis de mercado- de las opiniones de sus ciudadanos (Bouza, 1981, p. 37).

\section{Listado de Referencias bibliográficas}

Alcacer, J. (1991). El mundo del cartel. Madrid: Ediciones Granada.

Barnicoat, J. (2002). Los carteles. Su historia y su lenguaje. Barcelona: Editorial Gustavo Gili.

Bermúdez, D. (2015). "El surgimiento del designer". Designa 2015, International Conference on Design Research. Covilha: Universidade da Beira Interior, pp. 671-678.

Bierut, M. (1999), Classic writing on Graphic Design. New York: Allworth Press.

Bouza, F. (1981). “El cartel: retórica del sentido común”. Revista de Occidente, 5, abril, pp. 35-52.

Museo Nacional Centro de Arte Reina Sofía (2001) El cartel moderno francés: el espectáculo está en la calle. (Catálogo de exposición). Madrid.

Chaves, N. (1989). "Pequeña teoría del cartel”. Tipográfica, 9, pp. 1-6. 
Checa, A. (2015). El cartel: dos siglos de publicidad y propaganda. Sevilla: Advook Editorial.

Checa, A. (2017). Teoría e historia del cartel publicitario. Madrid: Editorial Síntesis.

Consuegra, D. (2006). El lenguaje del cartel. El cartel como fin y como medio. Bogotá: Auros Copias.

Coronado, D. (2012). La metáfora del espejo. Teoría e historia del cartel publicitario. Sevilla: Ediciones Alfar.

Eguizábal, R. (2014). El cartel en España. Madrid: Ediciones Cátedra.

Enel, F. (1974). El cartel: funciones, lenguaje, retórica. Valencia: Fernando Torres Editor.

Garrigan, J. (1975). Images of an era: The American Poster 1945-1975. New York: Museum of Modern Art.

Glaser, M. (1981). Graphis Posters'81. The International Annual of Poster Art. Zurich: Graphis Press Corp.

Gubern, R. (1987). La mirada opulenta. Exploración de la icooósfera contemporánea. Barcelona: Editorial Gustavo Gili.

Hinojosa, M. Á. (2012). "El poema, el cartel y el libro". Argumentos 25(68), enero-abril, pp. 243-247.

Hutchinson, H. (1968). Poster: An illustrated History from 1860. Londres: Studio Vista Ltd.

Iskin, R. (2014). The Poster: art, advertising, design, and collecting, 1860's-1900's. Hanover NH: Dartmouth College Press.

Moles, A. (1973). El afiche en la sociedad urbana. Buenos Aires: Paidós.

Morelos, J. (2016). El cartel político como memoria, identidad y patrimonio de la cultura mexicana (Tesis para optar al título de Doctor en Diseño y Creación). Manizales: Universidad de Caldas.

Müller-Brockmann, J. (1971). History of the Poster. Zurich: ABC Verlag.

Renau, J. (1937). Función social del cartel publicitario. Valencia: Tipografía Moderna.

Sontag, S. (1999). "Posters: Advertisement, Art, Political Artifact, Commodity”. Classic writings on Graphic Design. New York: Allworth Press.

Spiess, D. (1987). Affiches publicitaires: 100 ans d'histoire à travers l'Affiche. Lausana: Edita.

Abstract: This text is part of the Colombian Billboard doctoral research project at the University of Granada (Spain). It's about the modernization of Cali through the stamp (19101944). The main theme of this text is the history of graphic design and its content focuses on the poster as a cultural object and its main features. The poster is a window and a mirror in which we can understand a society in a specific period of time, reason why, the cartels have become reference of the modern world.

Keywords: Graphic design - Cali - modernization - culture - society 
Resumo: Este texto tem como tema principal a história do design gráfico, e seu conteúdo centram-se no cartaz como um objeto cultural e suas principais características. O cartaz é uma janela e um espelho em que podemos compreender uma sociedade em um determinado período de tempo, motivo por que, os cartéis tornaram-se referência do mundo moderno.

Palavras chave: Design gráfico - objeto cultural - mundo moderno.

[Las traducciones de los abstracts fueron supervisadas por el autor de cada artículo] 